\title{
Industry 4.0: Whose Revolution? The Digitalization of Manufacturing Work Processes'
}

I Sylvi Thun'

PhD, Research Scientist, SINTEF Digital, Technological Management, Norway

I Pål F. Kamsvåg

MSc, SINTEF Digital, Technological Management, Norway

I Birgit Kløve

MSc, Research Scientist, SINTEF Digital, Technological Management, Norway

I Eva A. Seim

PhD, Senior Research Scientist, SINTEF Digital, Technological Management, Norway

I Hans Y. Torvatn²

PhD, Research Manager, SINTEF Digital, Technological Management, Norway

\begin{abstract}
The ongoing digitalization of manufacturing work processes resulting from Industry 4.0 - defined as digitalization, automation, and data exchange in manufacturing-challenges how we see and define the role of operators and managers. Consequently, this study investigates the extent to which digital tools are used and available to managers and operators in manufacturing who are experiencing digitalization due to Industry 4.0 movements. A cross-sectional study of production managers and operators $(n=417)$ was conducted among 10 Norwegian manufacturing companies. Results from independent t-tests and Chi-square tests indicate that, compared with operators, production managers report higher satisfaction with different digitalization experiences, more extensive use of digital systems for registration and documentation, and greater availability of digital tools. Thus, digitalization and digital tools based on the Industry 4.0 concepts seem to have only reached the managerial level, and the revolution seems to be top down.
\end{abstract}

\section{KEYWORDS}

Autonomy / Competence / Digitalization / Digital Tools / ICT / Industry 4.0 / Manufacturing / Nordic work life / Operator role / Production management

\section{Introduction}

ver the last two decades, there has been massive progress in the fields of information technology, automation, robotics, Big Data, sensor technology (Internet of Things [IoT]), and artificial intelligence (Rüssmann et al. 2015). These

\footnotetext{
${ }^{1}$ You can find this text and its DOI at https://tidsskrift.dk/njwls/index.

${ }^{2}$ Corresponding authors: Sylvi Thun, Pb 4760 Torgarden, 7465 Trondheim, Norway (sylvi.thun@sintef.no) and Hans Y. Torvatn, Pb 4760 Torgarden, 7465 Trondheim, Norway (hans.torvatn@sintef.no).
} 
technological advances may be interpreted as prerequisites for the increasingly popular concept of Industry 4.0, which refers to the current trend of digitalization, automation, and data exchange in manufacturing (Kagermann et al. 2013; Schwab 2016). The ongoing digitalization in work life is pushing the industrial sector's already high rate of transformation even further, paving the way for new business models and making others redundant. For small and medium-sized enterprises (SMEs), which comprise a large part of industry in the Nordic countries, it is an enormous challenge to keep up with the pace of technological development. Greater demands are simultaneously being placed on the long-term sustainability of production and the utilization of resources. These digital transformations of manufacturing are challenging how we see and define the role of industrial workers-including both operators and the managers (Lall et al. 2017; Schneider 2018). Digitalization and automation in manufacturing are, however, not a new phenomenon. The development can be traced back to the late 1960s and the 'third industrial revolution', with the introduction of the first programmable logic controller, new complex industrial robots, and computers in manufacturing (Schneider 2018). Thus, it could be argued that digitalization has played an important role in forming work life within manufacturing for decades. Despite these historical facts, many researchers and experts believe that Industry 4.0 and recent technological advances will accelerate the pace of change with respect to future industrial work life (Kagermann et al. 2013). A shift from repetitive, low-skilled, and physical work to more complex and cognitive tasks is anticipated (Hecklau et al. 2016; Kagermann et al. 2013; Prinz et al. 2016). This shift is expected to contribute to more extensive decentralization and a greater degree of autonomy at the operator level (Gorecky et al. 2014; Tortorella et al. 2018).

One important and necessary step regarding the implementation of Industry 4.0 is to provide the necessary digital tools and well-functioning assistance systems to all workers within the organization. Furthermore, to fulfill the potential for increased value creation manifested in Industry 4.0, as well as increased autonomy, managers should ensure that their operators find available digital information to be useful and relevant. Sufficient and appropriate skills, competences, and tools are crucial for the Nordic region to maintain its high productivity in the future. An important assumption is therefore that manufacturing companies must facilitate the digital enhancement of their operators so that these operators can take greater responsibility in their companies. The use of technologies among operators is expected to increase in the coming years (Costantinescu et al. 2014; Herman et al. 2016; Kagermann et al. 2013; Prinz et al. 2016; Schneider 2018). Consequently, there is a need for deeper understanding of the prevalence of various technological solutions, as well as the consequences of such technologies among operators and in the interfaces between human, machine, and organization in the Nordic context. This will also affect the future role of the production manager (Lall et al. 2017), as operators will become responsible for overall production (rather than just a single machine) and for daily manufacturing operations (Oborski 2003).

The digital revolution, its possibilities, and implications have been put on the agenda in all Nordic countries (Digital21-group 2018; Iris Group 2015; Ministry of Economic Affairs and Employment of Finland 2018; Ministry of Industry, Business and Financial Affairs 2018). The importance, potential, and need for Industry 4.0 is also highlighted in the Norwegian Government's white paper A greener, smarter and more innovative

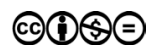


industry ${ }^{3}$. Industry 4.0 has also been topic for several conferences in Norway. However, there is a lack of empirical studies on this current trend of digitalization in the Norwegian manufacturing context. Hence, the purpose of this study is to investigate the extent to which digital tools are used and available to managers and operators. To do so, we focus on 10 manufacturing companies in Norway that are experiencing digitalization as a result of Industry 4.0 movements.

\section{The Concept, Vision, and Criticisms of Industry 4.0}

Recent progress in the field of information technology and the main technological drivers of Industry 4.0, IoT and cyber-physical systems (CPS) have paved the way for a 'fourth industrial revolution' (Hermann et al. 2016; Kagermann et al. 2013). The IoT makes it possible for sensors, smartphones, radiofrequency identification, and actuators to share information and interact with each other to achieve common objectives (Giusto et al. 2010). CPS refers to the integration of computation, networking, and physical processes (Lee 2008). These systems are merging the virtual and physical world through embedded networks that can control and monitor physical processes. CPS detect data from physical objects by means of sensors, and interact with physical processes via actuators, machinery, and human movements, creating a feedback loop (Thoben et al. 2017; Wang et al. 2015). Industry 4.0 and its components, IoT and CPS, are expected to contribute to substantial improvements to the industrial processes involved in manufacturing, engineering, supply chain management, and use of materials (Kagermann et al. 2013). Kagermann and colleagues (2013) argue that Industry 4.0 will lead to more dynamic engineering and business processes that enable flexible production in which manufacturers are able to respond to last-minute changes. It is also anticipated that more transparency within the organization and production processes will facilitate optimized and decentralized decision making (Hermann et al. 2016; Stock \& Seliger 2016). In spite of these positive implications, however, there is a need to be aware of some of the most problematized and discussed criticisms of Industry 4.0.

For instance, Industry 4.0 has been criticized for being unrealizable from both a technical and resource-related perspective. SMEs, due to their lack of resources, may face considerable challenges when trying to fulfill the visions of Industry 4.0 (Maier \& Student 2015). The limited financial capacities of SMEs make funding of comprehensive and expensive technological solutions challenging, and there is no indication that investments will dramatically increase budgets in the coming decades (Agiplan et al. 2015). According to Pfeiffer (2017), Industry 4.0 will spur economic growth, but the costs of implementing new technologies could reduce the overall growth effect in the short term. Furthermore, it is argued that many SMEs lack the necessary know-how and technical expertise to successfully implement Industry 4.0 technologies (Sommer 2015). Thus, some experts argue that the gap between large manufacturing companies and SMEs could potentially increase because of digitalization and Industry 4.0 (Hirsch-Kreinsen 2016). There are also several risks involved in Industry 4.0 movements, such as high investment costs, strong focus on the technological aspect, data

\footnotetext{
${ }^{3}$ Meld. St. 27 (2016-2017). A greener, smarter, and more innovative industry. https://www.regjeringen. no/en/dokumenter/meld.-st.-27-20162017/id2546209/
} 
safety issues, poor work conditions, and increased qualification requirements (Howaldt et al. 2017). Howaldt et al. (2017) also criticize visions of Industry 4.0 as being based on a one-sided, technology-oriented understanding of innovation that does not consider the complex interaction between social (the people) and technological innovations as a precondition for success of the new strategy. Our study acknowledges this latter criticism by taking a more dual-perspective approach and emphasizing the importance of the interaction between people and technological innovations. As a result of the ongoing implementation of Industry 4.0, with a strong focus on technological progress as the main driver of productivity growth in modern economies, increasing globalization, and increasing labor immigration, the Nordic model (elaborated on in the following section) is facing pressure. In the Nordic debate, the digitalization of industry and development of advanced manufacturing are taking an important position as significant factors for maintaining the nations' competitiveness and securing national jobs.

\section{The Nordic Work Life Model and the Changing Nature of the Work Process in Manufacturing}

In Norway, tripartite cooperation exists between authorities, employers, and employees, and work life is well-organized, with a high degree of trust between all parties. Norway also has an economic policy that entails high gender equality, solid public welfare systems that provide security and adaptability, and a working life with a high degree of coordination in wage formation and a high employment rate. As part of the Nordic work life model, which refers to a set of institutional and informal practices that create the foundation for a high level of employee participation (e.g., Bungum et al. 2015), there are many possibilities to optimize digital transformations. The cornerstones of Nordic work life-low power distance, mutual recognition, trust, and involvement (Sørensen et al. 2012) —represent several advantages that may have implications for the implementation of Industry 4.0's visions. The main competitive advantages of Norwegian companies come from their effective work processes based on high employee participation, equality, and the widespread use of autonomous teams (Levin et al. 2012). Highly skilled and autonomous employees who demonstrate cooperative creativity contribute to the emergence of flexible organizations that can operate effectively under rapidly changing conditions (Kasvio et al. 2012). Cooperation and participation at company levelincluding both representative participation (collaboration between employers and labor unions) and direct participation (the various mechanisms that empower employees to exert autonomy or influence their immediate work environment)—are also competitive advantages of the Nordic work life model.

Despite having higher labor costs compared to most other countries, Norwegian companies can compete in global and highly competitive markets by focusing on knowledge-based production of advanced, innovative, and custom-made products, targeting the high-end segment. Participation at the organizational level has also been considered a comparative advantage, as it may foster satisfaction and create involvement among employees, reduce resistance toward change, and lead to better solutions and innovations. Digital transformations affect the entire company, and implementation of new technology may result in resistance from different areas of the company (Matt et al. 2015). One way to deal with resistance is to encourage active involvement of the 
various stakeholders affected by the process (Matt et al. 2015). The Nordic work life model emphasizes the importance of wellbeing at work in the digital work environment, and the need for a participatory design in quality development (Haapakorpi \& Alasoini 2018). Effective and value-creating digitalization changes the nature of work and requires new kinds of management and modified working processes.

Norway has a strong and important industrial tradition in which competitiveness is largely based on efficient work processes through involvement, trust, and responsible operators. It is anticipated that, in future, operators on the shop floor will control more machines simultaneously and thereby know more about the production processes (Prinz et al. 2016). Hermann et al. (2016, p. 3933) argue that the role of workers on the shop floor will shift from 'operators of machines towards strategic decisionmakers and flexible problem solvers'. In order to handle the increasing complexity of production and surging data flows from CPS, operators need to be supported by well-functioning assistance systems (Lall et al. 2017; Prinz et al. 2016). Digital tools such as tablets, smartphones, and wearables could provide the necessary real-time information to operators, and thus contribute to decentralized decision making, a more rewarding work day, and enhanced operational efficiency (Costantinescu et al. 2014; Kagermann et al. 2013; Schneider 2018), and increase individuals' sense of control and autonomy over their work (Bordi et al. 2018). However, as previous research has shown, digital communication can not only act as a motivating job resource (Day et al. 2010; Demerouti et al. 2014), but also act as a job demand, requiring extra effort, disturbing workflow, and increasing the workload in a negative manner (Barley et al. 2011).

When the aim is to increase work performance and ensure more effective working hours in the production area, it is crucial that the production manager implements digital communication as a resource and not an exhausting demand. For instance, when employees are forced to use digital communication channels in work situations where they prefer to use other channels, symptoms of technostress may appear (see Tarafdar et al. 2011). However, digital tools and digital communication as a resource have the potential to ensure good information flow, facilitate useful and relevant information between workers, and provide flexibility in the work location (Day et al. 2010; Demerouti et al. 2014). Digital tools have the potential to positively impact work processes in industry. To fulfill the potential of digitalization, industry managers will need a profound understanding of the overall production processes and the organizational challenges across all departments within the company (Quint et al. 2015). Industry 4.0 could lead to more complicated fabrication, increased flow of data from production processes and intricate value chains, and more challenging coordination tasks for managers (Schneider 2018). Digital tools and assistance systems will be important necessities at the managerial level, but if operators are to be 'strategic decision makers and complex problem solvers,' technical assistance cannot stop at managerial levels-it must permeate the whole organization and include operators. The implementation of Industry 4.0 has a tremendous impact on industrial value creation, and it is important to understand the underlying dynamics of implementation (Müller et al. 2018).

Manufacturers emphasize the modernizing of production processes and the acceleration of automation and robotization (Lall et al. 2017). Development of the human role is, however, often neglected, perhaps due to the extensive technology- and business-oriented mindset frequently found among manufacturers, their research and 
development departments, and researchers. This is somewhat contradictory if there is a general understanding of Industry 4.0 as a concept that will contribute to more complex work for human workers. We argue that the visions of Industry 4.0 will be harder to achieve without anchoring the vision to workers at the floor level, and recent studies highlight this. Tortorella et al. (2018) found that the implementation of Industry 4.0, and similar high-tech approaches or concepts, is not in contradiction with the human aspects of an organization. In fact, their empirically backed findings indicate that, when implementing technologies that are central in Industry 4.0, companies that emphasize employees' involvement significantly improve their operational performance (Tortorella et al. 2018). Involving employees and offering them the opportunity to grow and develop could be regarded as critical success factors in the pursuit of becoming a 'smart factory' and fulfilling the visions of Industry 4.0.

The challenge for Norwegian industrial companies lies in maintaining and increasing productivity to prevent outsourcing, while at the same time enhancing job attractiveness, facilitating continuous improvement and innovation, and developing human skills and abilities. A previous study of three case companies found that highly motivated operators had an unsolicited need for information at right place at right time-a need that could negatively impact either the company's productivity and profits, or both (Lall et al. 2017). In this abovementioned study, there was no indication that these companies were behind the rest of Norwegian or European industry. Digitalization is making work more information-intensive, and operators will be required to process even more information in the future. Therefore, it is important that the information operators receive is precise and relevant to enabling their work processes. This leads us to the definition of digital information used in this study, which is relevant information through available and enabling digital tools.

Information systems seem to be tailored to the needs of management, rather than the needs of operators (Lall et al. 2017). To date, previous studies on Industry 4.0 have mainly contributed with knowledge on the basic concepts of Industry 4.0 and demonstration of its benefits, rather than providing empirical findings (Kamble et al. 2018). The present study will contribute more empirical knowledge on a topic that is currently highly theoretical. In the context of 10 manufacturing companies in Norway that are experiencing digitalization as a result of Industry 4.0 movements, this study will examine the extent to which digital tools provide beneficial information, and are used and available to managers and operators. On the basis of the above discussion, our hypotheses are as follows:

Hypothesis 1. There is a mean difference in how operators at the floor level perceive the benefits of digital information, compared to their production managers.

Hypothesis 2a. The use of digital tools as a source to gain information about production is associated with the employee's role (production manager vs. operator).

Hypothesis $2 \mathrm{~b}$. The quality of digital information is perceived differently by operators compared to production managers.

Hypothesis 2c. When planning production, the digital information made available depends on the employee's role (production manager vs. operator). 
Hypothesis $2 \mathrm{~d}$. The use of digital systems for registration and documentation is associated with the employee's role (production manager vs. operator).

Hypothesis 3. There is a mean difference between managers and operators in terms of how relevant they believe competence in information and communication technology (ICT) to be in relation to their everyday work.

Hypothesis 4. The benefits of digital information are predicted by competence in ICT, work process improvements, and planning of the employee's own workday, when controlling for the employee's age and role.

\section{Method}

\section{Participants and Procedure}

A cross-sectional study was carried out in 10 Norwegian manufacturing companies covering all organizational levels and roles $(\mathrm{N}=3188)$ in spring/summer 2017. The total sample consists of 1023 male and 160 female participants from a center for researchbased innovation called SFI Manufacturing $(\mathrm{n}=1183)$. The total response rate was $37 \%$. The participating companies have been given fictive names, A-E. SFI Manufacturing is a cross-disciplinary center for competitive high-value manufacturing in Norway, established in 2015. Its vision is that with the right products, technologies, and humans involved, sustainable and advanced manufacturing is possible in high-cost countries such as Norway. The aim is to strengthen manufacturing companies' ability to innovate. Participating companies are highly involved in SFI Manufacturing and contribute their own time and effort. In this study, the companies had the chance to propose content of the survey. Researchers developed the survey based on Industry 4.0 concepts, and after two rounds of revision, the companies approved the survey. The questionnaire contained questions covering the fields of product development, sustainability, and digitalization, the latter of which is relevant for this study. Given our focus on production and production workers, not all respondents were relevant in the sample. The subsample $(n=417)$ of interest comprised production managers $(\mathrm{n}=246$, female $8.54 \%)$ and operators working in the production area $(n=171$, female $12.28 \%)$. When looking at the whole sample together, the most frequent age range was $41-50$ years. In more detail, respondents representing operators were aged 16 to $>60$ years, while production managers were aged 21 to $>60$ years.

The questionnaire formulated in Norwegian was initially distributed via the work email addresses of the workers, directly by the researchers through an electronic survey tool. Included in the invitation was an endorsement from the top manager of the enterprise to participate; this was also intended to demonstrate that the email was not spam. However, not all companies had email addresses for all employees, with missing addresses typically for operators. It was agreed that private email addresses or phone numbers should not be used as a basis for distributing the survey. Thus, a few of the companies preferred to distribute the survey in paper format or offer a Web-based solution where respondents could use a computer to fill in their answers. It should be noted that more than $90 \%$ of responses were generated from the work emails. Nevertheless, the 
additional methods were important to smaller companies. To increase the response rate, two email reminders were distributed. After two rounds of data collection, a response rate analysis was conducted, and a final set of reminders was distributed to all companies. However, for company A and company E, an additional round was undertaken. For company A3, we added the possibility to answer a paper-based questionnaire, which resulted in an additional 14 responses. A separate open questionnaire allowed employees without email addresses to answer on a separate computer during work hours. This increased the total number of people asked, as well as easing the process for those who did not regularly use email. The reminders increased the response rate. Participants were asked to provide their responses anonymously. Informed consent was required prior to their participation in the electronic questionnaire. The Norwegian Social Science Data Service approved the study.

Participating companies are leading industrial actors with the aim of developing the industry of the future by cooperating with researchers. Thus, the respondents in this sample were at the forefront of the Norwegian manufacturing industry, rather than representing the industry average. A total of 10 companies, of varying size, participated. As summarized in Table 1, the smallest participated company consist of 23 targeted employees, whereas the largest participated company consist of 2121 targeted employees. Three of these were enterprises within the same consortium (labeled A1 to A3 in Table 1). Table 1 details the sample size distribution, the number of responses collected, and the response rate percentage for each specific company, and for the sample as a whole.

Table I Details of company and total sample response rate

\begin{tabular}{lccc}
\hline & $\begin{array}{c}\text { Number of } \\
\text { employees invited } \\
\text { to participate }\end{array}$ & $\begin{array}{c}\text { Number of } \\
\text { responses } \\
\text { collected }\end{array}$ & $\begin{array}{c}\text { Response rate } \\
\text { within the } \\
\text { company (\%) }\end{array}$ \\
\hline Company AI & 2121 & 579 & 27 \\
Company A2 & 118 & 64 & 54 \\
Company A3 & 51 & 15 & 29 \\
Company B & 473 & 228 & 48 \\
Company C & 180 & 94 & 52 \\
Company D & 71 & 57 & 80 \\
Company E & 51 & 50 & 98 \\
Company F & 58 & 47 & 81 \\
Company G & 42 & 27 & 64 \\
Company H & 23 & 22 & 96 \\
\hline Sample population $(\mathrm{N})$ & 3188 & & \\
\hline Total study sample $(\mathrm{n})$ & \multicolumn{4}{|l}{} \\
\hline Total response rate & &
\end{tabular}

The 10 companies are all private manufacturing enterprises. Production in the manufacturing industry is often located in rural or small towns, and not in the central parts/big cities of Norway. The companies have various ownership structures, from family owned 
to internationally owned. Regardless of their current ownership, they all originated as locally owned enterprises/subsidiaries of local enterprises. The participating companies have long industrial traditions and histories. They have found ways to keep up with ongoing industrial changes. Their main work processes include melting metal, building ships, making furniture, or building car parts. Some of the companies provide services in addition, such as research \& development, design, planning, etc., but these additional services are always connected to the physical product that the companies sell on the open market.

\section{Measures}

The benefits of digital information were measured with four items. Respondents were asked to consider the extent to which digital tools are useful in their work by responding to four questions; for instance, 'to what extent do digital tools: (1) help improve the quality of your work, (2) contribute to work being done faster, (3), help you to complete work you couldn't do without such tools, and (4) improve the safety of work routines?' The Cronbach's $\alpha$ value for the instrument was 0.90 . Answers were given on a five-point Likert scale ranging from (1) to a very small extent to (5) to a very great extent.

To measure digital use, several questions were used. For example, the respondents were asked to indicate whether they used digital tools to find information about their production work on a categorical scale of yes or no.

Digital systems for registration and documentation was measured with four items, where the responses could be given as either yes, digital; or no, not digital. An example question is, 'During production, do you have systems in place (1) to register and report the quality of the product, (2) for ordering tools/components needed to perform the work task, (3) for planning production, and/or (4) for planning maintenance?'

The quality of the information obtained from digital tools consisted of three items. For example, 'Is the information you receive from digital tools (1) good enough to do what you want to do, (2) up to date, and (3) distinct and comprehensible?' Respondents were asked to choose one of three items and answer yes (1), partly (2), or no (3). The categories 'partly' and 'no' were later merged into one category because 'no' had too few answers to stand alone as a category in a Chi-square test. Instead of deleting these answers, we argue that since we are interested in respondents who were certain about how they perceived the quality, compared with those who were less sure, it was more valuable to merge the 'partly' and 'no' categories.

The availability of digital information was measured with one item, to which respondents answered yes or no to each part: 'Is digital information physical available when you plan production by means of (1) portable digital information technology (that can be worn on the body), (2) your work station, (3) distribution in the production hall, and (4) at a central place (break room, control room, or similar)'.

Competence in ICT was measured with one item: How relevant do you believe mastery of competence in ICT are to your everyday work? Answers were given on a five-point Likert scale ranging from (1) to a very low degree to (5) to a very high degree.

Work process improvements was measured with one item: 'In your workplace, employees want to use their skills and knowledge to constantly improve the way they work'. Answers were given on a five-point Likert scale ranging from (1) totally disagree to $(5)$ totally agree. 
Autonomy to plan own workday was measured with one item: 'In your opinion, how important are skills related to planning your workday?' Answers were given on a five-point Likert scale ranging from (1) not very important to (5) very important.

\section{Statistical Analysis}

Independent t-tests (two-tailed) were used to assess mean differences in perceived benefits of digitalization and competence in ICT between production managers and operators. Chi-square tests were used to analyze whether there is an association between digital use and the respondent's role (production manager versus operator). Pearson's correlations were used to assess the association between the variables measured using a Likert scale. Regression analysis was conducted to test the predictor variables' influence on the dependent variable, benefits of digital information. The tolerance and variance inflation factor values indicated no problem with multicollinearity. All independent variables measured with response scales had sufficiently normal distribution to permit parametric tests. All analyses were conducted with IBM SPSS Statistics, version 24.

\section{Results}

The sample reported the highest mean score for work process improvement $(M=4.16$, $S D=0.86)$, followed by perceived benefits of digitalization $(M=4.05, S D=1.02)$, planning of own workday $(M=3.97, S D=0.82)$, and finally competence in ICT $(M=3.68$, $S D=0.95)$. Regarding whether digital use was prevalent among production managers and operators, $87 \%(n=246)$ of production managers and $83.5 \%(n=170)$ of operators said they use digital tools as a source to find information about production work. In total, $85.6 \%(n=357)$ of respondents used digital tools as a source to find information about production work.

Table 2 reports the frequencies of reported quality of information obtained from digital tools among production managers and operators. The most prevalent answer among production managers was no; however, the answers were similarly distributed in the two categories. Among operators, the most frequent answer was yes, but again, the answers were distributed similarly in the two categories. A general tendency was for managers to be more negative toward the quality of information gained from digital tools than were operators.

Table 2 Frequencies of the reported quality of information obtained from digital tools among production managers versus operators

\begin{tabular}{lcccc}
\hline Variable & \multicolumn{2}{c}{ Production Manager } & \multicolumn{2}{c}{ Operator } \\
\hline Is the information you receive from ... & Yes (\%) & No (\%) & Yes (\%) & No (\%) \\
\hline ... digital tools good enough to do what you & & & & \\
want to do? & $103(48.8)$ & $110(51.6)$ & $75(54.7)$ & $62(45.3)$ \\
... digital tools up to date? & $93(45.6)$ & $111(54.4)$ & $66(54.4)$ & $73(52.5)$ \\
... digital tools distinct and comprehensible? & $96(47.1)$ & $108(52.9)$ & $73(52.5)$ & $66(47.5)$ \\
\hline
\end{tabular}


Table 3 reports the frequencies related to whether digital information is physically available to production managers and operators. Both production managers and operators reported that the traditional workstation is most frequent place at which they find relevant and available digital information. Portable digital information technology (that can be worn on the body) was most frequently reported in the 'no' category in both groups, indicating that there is still potential to use more enabling technologies, such as smart glasses, voice control, virtual reality, and augmented reality, in the Norwegian manufacturing industry. The findings also indicate some potential to empower the production hall with more beneficial digital tools.

Table 3 Frequencies of digital information availability among production managers and operators

\begin{tabular}{|c|c|c|c|c|}
\hline \multirow{2}{*}{$\begin{array}{l}\text { Variable } \\
\text { Is digital information physical available } \\
\text { when you plan production via ... }\end{array}$} & \multicolumn{2}{|c|}{$\begin{array}{l}\text { Production Manager } \\
(\mathrm{n}=176)\end{array}$} & \multicolumn{2}{|c|}{$\begin{array}{l}\text { Operator } \\
(n=66)\end{array}$} \\
\hline & Yes (\%) & No $(\%)$ & Yes (\%) & No $(\%)$ \\
\hline $\begin{array}{l}\text {... portable digital information technology } \\
\text { (that can be worn on the body) }\end{array}$ & $25(14.2)$ & |5| (85.8) & $3(4.5)$ & $63(95.6)$ \\
\hline ... your work station & $149(84.7)$ & $27(15.3)$ & $53(80.3)$ & $13(19.7)$ \\
\hline ... distribution in the production hall & $49(27.8)$ & $127(72.2)$ & $10(15.2)$ & $56(84.9)$ \\
\hline $\begin{array}{l}\text {... a central place (break room, control } \\
\text { room, or similar) }\end{array}$ & $54(30.7)$ & $122(69.3)$ & $21(31.8)$ & $45(68.2)$ \\
\hline
\end{tabular}

Hypothesis 1 posits that there is a systematic difference in how production managers versus operators report digital tools as beneficial to their workday. Findings from an independent $\mathrm{t}$-test confirmed that there were indeed systematic differences in perceptions in this regard. Production managers reported greater benefits of digitalization $(M=4.16$, $S D=0.93)$ than did operators $(M=3.75, S D=0.99), t(412)=4.22, \mathrm{p}<0.001$, which represents a moderate effect size (Cohen's $d=0.43$ ). This result indicates that production managers reported higher satisfaction with digitalization than operators in the 10 Norwegian manufacturing companies considered.

Hypotheses $2 \mathrm{a}$ and $\mathrm{b}$ indicated that the use of digital tools as a source to gain information about production, and the quality of digital information, are associated with the employee's role (production manager versus operator). Findings from the Chi-square test indicated that there were no significant associations between the role and use of digital tools as a source of information about production $\left[\chi^{2}(1)=0.98, \mathrm{p}=0.40\right.$, n.s.], nor in perceptions of quality of information from digital tools $\left[\chi^{2}(1)=1.36, p=0.27\right.$, n.s.]. Hypothesis $2 \mathrm{a}$ and $2 \mathrm{~b}$ were thus not supported.

However, when planning production, the digital information made available is to some degree related to the role of employment (production manager versus operator). There was a significant association between the type of employment and whether the workers found digital information to be available, including in the form of portable digital information technology (that can be worn on the body), $\chi^{2}(1)=4.28, \mathrm{p}<0.05$, or in the production hall $\chi^{2}(1)=4.19, \mathrm{p}<0.05$. There was no significant association between the type of employment and whether the workers found digital information to be available at their workstation $\left[\chi^{2}(1)=0.66, p=0.44\right.$, n.s.] or at a central place (break room, control room, or similar) $\left[\chi^{2}(1)=0.03, \mathrm{p}=0.88\right.$, n.s.]. Hypothesis $2 \mathrm{c}$ is therefore partly supported, 
as responses regarding two out of four digital information availability types were significant. This indicates that production managers found digital tools to be more available than did operators when planning production, but only regarding certain types of availability.

Hypothesis $2 \mathrm{~d}$ indicated that the use of digital systems for registration and documentation are associated with the role of employment. Systems for registering and reporting the quality of the product $\left[\chi^{2}(1)=6.08, \mathrm{p}<0.05\right]$, for ordering tools $/ \mathrm{com}$ ponents needed to perform the work task $\left[\chi^{2}(1)=20.76, \mathrm{p}<0.001\right]$, for planning production $\left[\chi^{2}(1)=18.09, \mathrm{p}<0.001\right]$, and for planning the maintenance $\left[\chi^{2}(1)=7.09\right.$, $\mathrm{p}<0.01$ ] were significantly associated with the type of employment, since production managers reported greater use of digital systems for registration and documentation compared to operators. Thus, Hypothesis $2 \mathrm{~d}$ is supported.

Findings from an independent t-test also confirmed systematic differences in how important production managers versus operators believe competence in ICT is in mastering their daily work tasks. Production managers experienced greater benefits of ICT competence $(M=3.85, S D=0.84)$ than did operators $(M=3.45, S D=1.06), t(414)=4.07$, $\mathrm{p}<0.001$; the results represent a moderate effect size (Cohen's $d=0.43$ ). Hypothesis 3 is therefore supported.

Hypothesis 4, which suggested that benefits of digital information are predicted by competence in ICT, work process improvements, and planning of own workday, when controlling for employee's age and role, was partly supported. Table 4 summarizes the correlations of the study variables, which indicate that the variables are positively related to each other. Specifically, as summarized in Table 5, 17.4\% of the variance of benefits of digital information was predicted by the independent variables. The strongest predictor of benefits of digital information was competence in ICT $(\beta=0.30, \mathrm{p}<0.001)$; this was a significant predictor together with autonomy to plan of own workday $(\beta=0.10$, $\mathrm{p}<0.05)$ and the control variable role of employment $(\beta=-0.13, \mathrm{p}<0.01)$.

Table 4 Pearson correlations of the study variables

\begin{tabular}{lcccc}
\hline Measure & $\mathbf{I}$ & $\mathbf{2}$ & $\mathbf{3}$ & $\mathbf{4}$ \\
\hline I. Benefits of digital information & - & & & \\
2. Competence in ICT & $0.38^{*}$ & - & & \\
3. Work process improvements & $0.18^{*}$ & $0.22^{*}$ & - & - \\
4. Autonomy to plan own workday & $0.24^{*}$ & $0.37^{*}$ & $0.22^{*}$ & - \\
\hline
\end{tabular}

${ }^{*} \mathrm{p}<0.01$.

Table 5 Regression analysis of the predictors of benefits of digital information

\begin{tabular}{lcccc}
\hline Measure & $\boldsymbol{\beta}$ & $\mathbf{p}$ & $\mathbf{9 5 \%} \mathbf{C l}$ & $\mathbf{A d j}^{\mathbf{2}} \mathbf{R}^{\mathbf{2}}$ \\
\hline Competence in ICT & 0.30 & 0.001 & {$[0.21$ to 0.42$]$} & \\
Work process improvements & 0.08 & 0.07 & {$[-0.01$ to 0.20$]$} \\
Autonomy to plan own workday & 0.10 & 0.034 & {$[0.01$ to 0.24$]$} \\
Role of employment & -0.13 & 0.004 & {$[-0.44$ to -0.08$]$} \\
Gender & 0.003 & 0.95 & {$[-0.30$ to 32] } \\
\hline
\end{tabular}


Altogether, the significant findings in this study highlight that production managers find digitalization to be more useful, available, and beneficial compared with operators. The findings also indicate that the benefits of digital information are predicted by how the individual's competence in ICT impacts their daily work tasks, and enables them to be proactive and have the flexibility to plan their own workday.

\section{Discussion}

Digitalization can bring enormous opportunities to develop a new, smarter, and more sustainable industrial sector in the Nordic countries. This article highlights an unused potential in the process of digitalization. Findings revealed that production managers tend to report higher satisfaction with different digitalization experiences compared with operators in the 10 Norwegian manufacturing companies studied. For instance, production managers report greater use of digital systems for registration and documentation than operators. Further, two out of four digital tools were experienced as being more available among production managers compared with operators. The fact that production managers find digital tools to be more available than do operators when planning production is contrary to expectations, since we argue that it is operators that need to be supported in their work process, since they are the ones out in the production area who require information, rather than managers. It seems that Norwegian manufacturing companies have potential to use more enabling technologies, such as smart glasses, voice control, virtual reality, and augmented reality. The findings reveal a potential to empower both 'the body' and the production hall with more beneficial digital tools.

There were also systematic differences among production managers and operators in how important they believe their competence in ICT to be in impacting how they master their daily work tasks. In sum, the findings indicate that digitalization and ICT systems based on Industry 4.0 visions are designed by and intended more for managers than for operators. This is somewhat contrary to expectations if there is a general understanding of Industry 4.0 as a concept that will contribute to more complex work for operators (Gorecky et al. 2014; Tortorella et al. 2018). Training and development tailored toward Industry 4.0 specific competencies and skills can also increase successful implementation of related technologies (Müller et al. 2018; Stock \& Seliger 2016). Digital training in real work settings is one way to ensure efficient use of digital tools. The findings from the regression analysis show that personal skills and expertise have implications for how digital tools can help operators improve the quality of their work, complete work more quickly, experience new job content, and contribute to safety in work routines. This has implications for how the industry can profit from ongoing digitalization processes.

In future, there will be more need for multidisciplinary operators with technical, analytical, and ICT skills, and less need for traditional craftsmen. The importance of operators will increase, as they become responsible for the whole production process, and not just a single machine (Oborski 2003). However, our findings indicate that the vision and complexity have not (yet) reached the production floor level. Although we studied highly developed manufacturing companies in Norway-a society with strong values of autonomy and employee participation-it seems that the visions of Industry 4.0 lack anchoring at the operational level. According to Müller et al. (2018), the 
implementation of Industry 4.0 has a tremendous impact on industrial value creation, and it is important to understand the underlying dynamics of implementation. In addition, the number of managers in production is expected to decrease, leaving operators with responsibility for daily manufacturing operations (Oborski 2003). This, together with our findings, indicates that Industry 4.0 implementation should focus much more on the operational level in future.

By moving management decisions partly to the production floor, companies will enable quick responses and increased flexibility, and free up management capacity that can be invested in other areas. High-tech industrial production, which entails a rapid rate of change and capabilities for innovation and utilization of new technology, is important to keep industrial production in the Nordic countries. For the increased digital technology to result in positive effects in organizations, the technical design question must be preceded by the social design question (Govers \& Amelsvoort 2017). In order to convince operators of the beneficial nature of Industry 4.0, managers should ensure good training settings and address operators' concerns. For instance, as shown by our findings, giving operators autonomy to plan their own workday increases the benefits of digital information. Conversely, a lack of employee qualifications and acceptance might impact the implementation stage (Müller et al. 2018) and future success.

The ( $\mathrm{r}$ )evolution of Industry 4.0 in future will benefit from greater involvement from operators. In particular, there is tremendous potential in Norway, as the cornerstones of the Nordic model (Levin et al. 2012; Sørensen et al. 2012) offer an advantage in terms of successfully implementing elements of Industry 4.0 by gaining context-specific knowledge as a result of high participant involvement and trust. If digitalization and ICT systems are not implemented with the operator in mind, it can result in inefficiency and suboptimal use of workers' capabilities and potential (Lall et al. 2017). In a highcost country such as Norway, ensuring effective production lines contributes to keeping production and industry in the country. From an operational perspective, Industry 4.0 can help achieve and facilitate process optimization before value creation is realized in practice (Müller et al. 2018). In order to gain more benefits from Industry 4.0, more efforts are needed at both the managerial and the operational level (Kagermann et al. 2013; Stock \& Seliger 2016). Less monotonous and repetitive tasks might result in more engaged operators (Kagermann et al. 2013; Müller et al. 2018; Stock \& Seliger 2016), and digital tools have the potential to ensure more productive operators (Costantinescu et al. 2014; Kagermann et al. 2013; Schneider 2018). For instance, digital communication can increase operators' sense of control and autonomy over their work (Bordi et al. 2018). However, new digital practices need to be developed with the operator in mind, and operators must be involved in the process of finding out what best fits them at floor level, and in relation to their work.

\section{Methodological Limitations}

The findings in this paper are based on cross-sectional data, which precludes any conclusions regarding causality. As the concepts are subjective and related to the individuals' experiences, such as perceived benefits of digitalization, we argue that self-reports are valid measures. However, self-reports may increase the risk of common method variance in terms of recall bias and socially desirable responses (Podsakoff et al. 2003). To 
limit methodological bias, assuring respondents anonymity aims to decrease strategic responding and increases the presence of valid answers (Podsakoff et al. 2003). We suggest that it seems unlikely that respondents would over-report their experience with digitalization in an anonymous and confidential study.

Another limitation pertains to the moderate response rate, which could have increased the likelihood of random errors and decreased the accuracy of the estimates. On the basis of a response analysis of 490 studies, Baruch and Holtom (2008) found that the average response rate for studies utilizing data collected from organizations is $35.7 \%$; according to this guidance, our response rate falls within these ranges. Nevertheless, the rate may have had implications for our findings. Strategies were implemented to improve the response rate; for example, instead of using paper-based surveys, we used a Web-based collection. According to Baruch and Holtom (2008), use of email, phone, and Web yields a higher response rate than using postal delivery. Together with the reminders, all enterprises received a tailor-made report of their scores relative to the total. After the reports had been distributed, we found that they had been presented and discussed in the companies. While the companies struggled to build a digitalization strategy from the results, they did not question or reject the results. Thus, we conclude that while response rates ideally should have been higher, overall the findings are a good indicator of how digitalization is experienced by the enterprises. For practical reasons, unfortunately, we did not obtain an exact number of production managers and operators in the companies. We argue, however, that despite the moderate response rate, we have provided valuable insights on a topic that has received relatively little empirical attention. However, generalization of the findings should be done with caution. Given the type of enterprise participating in the survey, the study is not representative of the Norwegian manufacturing industry as a whole. The companies measured are more interested in research than average, and are expected to have higher use of technology than average. Thus, future research would benefit from more international comparative studies on Industry 4.0 movements.

\section{Theoretical and Practical Implications}

As previously addressed and discussed, this study provides empirical findings that are relevant for digitalization and the implementation of Industry 4.0 movements. This paper adds to the small body of literature that has addressed digitalization in manufacturing companies, and the differences experienced between operational managers and operators. By conducting this research in Norway, we contribute empirical insights that highly developed manufacturing companies strive on getting the most out of Industry 4.0. According to our findings, digitalization and ICT systems based on Industry 4.0 visions are designed by and intended more for managers than for operators. Our empirical findings contribute knowledge that reduces a research gap in the Industry 4.0 literature. Indeed, employment opportunities in the Nordic industrial sector have, and will further be, redistributed from simpler manufacturing jobs to more highly qualified, often service-oriented jobs.

New technology is expected to change Nordic work life and may give Nordic manufacturing companies a competitive advantage (Iris Group 2015). However, this will require companies to exploit the competitive advantage that lies in the Nordic model 
by digitally enhancing operators' approaches to work so that they can take even more responsibility for the production system and make decisions for efficient production. There is potential for more enabling technologies in a production setting; however, managers should also be aware of the pitfalls when implementing new tools. Müller et al. (2018) stressed the need to establish a collaborative, explorative, and entrepreneurial mindset among a company's most important resource-employees-when implementing Industry 4.0 concepts. They also highlighted the need for top management to promote change-management activities and processes to create organizational structures that meet the requirements for connected value creation.

\section{Conclusion}

This paper explored the empirical reality of the extent to which digital tools give beneficial information, and are used by and available, to managers and operators in 10 manufacturing companies in Norway who have experienced digitalization as a result of Industry 4.0 movements. The Norwegian companies in question are motivated regarding, and dedicated to, Industry 4.0. They are among the elite in Norway, and most are competing in the worldwide market. All have decades of digitalization behind them, if we include their earlier work and robotization. They are all also aware and supportive of Nordic work life model values, are highly unionized, and are committed to values of workplace democracy and participation. They strive to develop autonomous work teams, believing that an autonomous and competent work force and relatively flat hierarchy is of major importance to their competitive advantage. The enterprises are digital, although piles of paper still exist. Workers in Norway generally support the introduction and use of digital tools, and there is a general positive attitude toward digitalization (Torvatn et al. 2017). Nevertheless, our findings show that there is a gap between the needs and wishes of operators in the Industry 4.0 setting, and the reality of the tools offered. This paper underscores the need for developing digital tools that support the work of operators, enabling them to have increased situational awareness, decision authority, and autonomy. Industry 4.0 is too important to be left to middle managers' and analysts' desks.

\section{References}

Agiplan, Fraunhofer IML \& Zenit (2015). Erschileßen der Potentiale von Industrie 4.0 im Mittelstand. Studie im Auftrag des BMWI, Dortmund. [Tapping the Potential of Industry 4.0 in the SME Sector. A study on behalf of the BMWI]. Available at: https://www.bmwi.de/ Redaktion/DE/Publikationen/Studien/erschliessen-der-potenziale-der-anwendung-von-industrie-4-0-im-mittelstand.pdf? blob=publicationFile\&v=5 (Accessed January 2019).

Barley, S. R., Meyerson, D. E. \& Grodal, S. (2011). Email as a source and symbol of stress, Organization Science 22(4): 887-906. doi: https://doi.org/10.1287/orsc.1100.0573.

Baruch, Y. \& Holtom, B. C. (2008). Survey response rate levels and trends in organizational research, Human Relations 61: 1139-1160. doi: https://doi.org/10.1177/0018726708094863.

Bordi, L., Okkonen, J., Mäkiniemi, J-P. \& Heikkilä-Tammi, K. (2018). Communication in the digital work environment: implications for wellbeing at work, Nordic Journal of Working Life Studies 8(3): 29-48. doi: https://doi.org/10.18291/njwls.v8iS3.105275. 
Bungum, B., Forseth, U. \& Kvande, E. (2015). Internasjonalisering og den norske modellen, in B. Bungum, U. Forseht, \& E. Kvande (Eds.), Den norske modellen. Internasjonalisering som vitalisering [The Norwegian model. Internationalization as revitalization]: 14-35, Bergen: Fagbokforlaget.

Constantinescu, C. L., Francalanza, E., Matarazzo, D. \& Balkan, O. (2014). Information support and interactive planning in the Digital Factory: Approach and industry-driven evaluation, in $8^{\text {th }}$ International Conference on Digital Enterprise Technology - DET - Disruptive Innovation in Manufacturing Engineering towards the $4^{\text {th }}$ Industrial Revolution.

Day, A., Scott, N. \& Kelloway, E. K. (2010). Information and communication technology: implications for job stress and employee well-being, in P. L. Perrewé \& D. C. Ganster (Eds.) New Developments in Theoretical and Conceptual Approaches to Job Stress, Emerald Group Publishing Limited: 317-350. doi: https://doi.org/10.1108/s1479-3555 (2010)0000008011.

Demerouti, E., Derks, D., Lieke, L. \& Bakker, A. B. (2014). New ways of working: Impact on working conditions, work-family balance, and well-being, in C. Korunka \& P. Hoonakker (Eds.) The Impact of ICT on Quality of Working Life, Dordrecht: Springer: 123-141. doi: https://doi.org/10.1007/978-94-017-8854-08.

Digital21-group (2018). Digital 21, Available at: https:/digital21.no/wp-content/uploads/ 2018/09/Digital21 strategi 2018.pdf.

Giusto, D., Iera, A., Morabito, G. \& Atzori, L. (2010). The Internet of Things, New York: Springer Science + Business Media, LCC.

Gorecky, D., Schmitt, M., Loskyll, M. \& Zühlke D. (2014). Human-machine interaction in the industry 4.0 era, in $12^{\text {th }}$ IEEE International Conference on Industrial Informatics, Porto Alegre: 289-294. doi: https://doi.org/10.1109/INDIN.2014.6945523.

Govers, M. \& Amelsvoort, P. (2017). A socio-technical perspective on the design of it architecture: the lowland lens. In Proceedings of the 25th European Conference on Information Systems (ECIS), Guimarães, Portugal. ISBN 978-989-20-7655-3 Research Papers. doi: https://aisel.aisnet.org/ecis2017 rp/15.

Haapakorpi, A. \& Alasoini, T. (2018). Work organization and technology: introduction to the theme of the special issue, Nordic Journal of Working Life Studies 8(3): 1-6. doi: https://doi.org/10.18291/njwls.v8iS3.105273.

Hecklau, F., Galeitzke, M., Flachs, S., \& Kohl, H. (2016). Holistic approach for human resource management in Industry 4.0, Procedia CIRP, 54: 1-6. doi: https://doi.org/10.1016/j. procir.2016.05.102.

Hermann, M., Pentek, T. \& Otto, B. (2016). Design principles for Industrie 4.0 scenarios, in $4^{\text {th }}$ Hawaii International Conference on System Sciences (HICSS). IEEE (Eds), Koloa, HI: HICSS: 3928-3937. doi: https://doi.org/10.1109/HICSS.2016.488.

Hirsch-Kreinsen, H. (2016). 'Industry 4.0' as promising technology: emergence, semantics and ambivalent character, Soziologisches Arbeitspapiere, 48 [Sociological Working papers 48], Dortmund: Dortmund University library. ISSN 1612-5355.

Howaldt J., Kopp R. \& Schultze J. (2017). Why Industrie 4.0 needs workplace innovation - a critical essay about the German debate on advanced manufacturing, Workplace Innovation. Aligning Perspectives on Health, Safety and Well-Being, Switzerland: Springer. doi: https://doi.org/10.1007/978-3-319-56333-6 4 .

Iris Group. (2015). Digitalization and automation in the Nordic manufacturing sector - Status, potentials and barriers, Denmark: TemaNord, 1-115. 578 ISBN 978-92-893-4422-7.

Kagermann, H., Wahlster, W. \& Helbig, J. (2013). Recommendations for implementing the strategic initiative Industrie 4.0: securing the future of German manufacturing industry (Final report from the Industrie 4.0 Working Group), München: National Academy of Science and Engineering. 
Kamble, S. S., Gunasekaran, A., \& Gawankar, S. A. (2018). Sustainable Industry 4.0 framework: a systematic literature review identifying the current trends and future perspectives, Process Safety and Environmental Protection 117: 408-425. doi: https://doi.org/10.1016/j. psep.2018.05.009.

Kasvio, A., Gonäs, L., \& Skorstad, E. (2012). In search of the Nordic working life model; introduction to the thematic issue, Nordic Journal of Working Life Studies 2(4): 1-19. doi: https://doi.org/10.19154/njwls.v2i4.2302.

Lall, M., Torvatn, H., \& Seim, E. (2017). Towards Industry 4.0: Increased Need for Situational Awareness on the Shop Floor. Springer International Publishing AG 2017, H. Lödding et al. (Eds.): APMS 2017, Part I, IFIP AICT 513, pp. 322-329, 2017. doi: https://doi. org/10.1007/978-3-319-66923-6 38.

Lee, E. A. (2008). Cyber Physical Systems: Design Challenges, Electrical Engineering and Computer Sciences, Berkeley, CA: University of California.

Levin, M., Nilssen, T. G., Elvemo, J. \& L. Øyum. (2012). Demokrati i arbeidslivet: Den norske samarbeidsmodellen som konkurransefortrinn. [Democracy in the work life: the Norwegian cooperation model as a competitive advantage], Bergen: Fagbokforlaget.

Maier, A. \& Student, D. (2015). Industrie 4.0 - der große Selbsbetrug, Manager Magazin, Available at: http://www.manager-magazin.de/magazin/artikel/digitale-revolution-industrie-4-0-ueberfordert-deutschen-mittelstand-a-1015724.html (Accessed January 2019). [Industry 4.0 - the big self-deception, Manager Magazin].

Matt, C. Hess, T. \& A. Benlian. (2015). Digital transformation strategies, Business Information Systems Engineering 57: 339-343. doi: https://doi.org/10.007/s12599-015-0401.5.

Ministry of Economic Affairs and Employment of Finland. (2018). Digital Finland framework. Framework for turning digital transformation to solutions to grand challenges, Available at: https://www.businessfinland.fi/globalassets/julkaisut/digital-finland-framework.pdf.

Ministry of Industry, Business and Financial Affairs, The Danish Government. (2018). Strategy for Denmarks Digital Growth, Available at: https:/eng.em.dk/media/10566/digital-growth-strategy-report uk web-2.pdf.

Müller, J. M., Kiel, D., and Voigt, K-I. (2018). What drives the implementation of Industry 4.0 ? The role of opportunities and challenges in the context of sustainability, Sustainability, 10: 247-271. doi: https://doi.org/10.3390/su10010247.

Oborski, P. (2003). Social-technical aspects in modern manufacturing, International Journal of Manufacturing Technology 22: 848-854. doi: https://doi.org/10.1007/s00170-0031573-6.

Pfeiffer, S. (2017). The vision of 'Industrie 4.0' in the making - a case of future told, tamed, and traded, Nanoethics 11: 107-121. doi: https://doi.org/10.1007/s11569-016-0280-3.

Podsakoff, P. M., MacKenzie, S. B., Lee, J-Y., \& Podsakoff, N. P. (2003). Common method biases in behavioral research: a critical review of the literature and recommended remedies, Journal of Applied Psychology, 88: 879-903. doi: https://doi.org/10.1037/00219010.88.5.879.

Prinz, C., Morlock, F., Freith, S., Kreggenfeld, N., Kreimeier, D., \& Kuhlenkötter, B. (2016). Learning factory modules for smart factories in Industrie 4.0, Procedia CIRP 54: 7-12. doi: https://doi.org/10.1016/i.procir.2016.05.105.

Quint, F., Sebastian, K \& Gorecky, D. (2015). A mixed-reality learning environment, Procedia Computer Science 75: 43-48.

Rüssmann, M., Lorenz, M., Gerbert, P., Waldner, M., Justus, J., Engel, P. \& Harnisch, M. (2015). Industry 4.0 - The Future of Productivity and Growth in Manufacturing Industries, The Boston Consulting Group, BCG.

Schneider, P. (2018). Managerial challenges of Industry 4.0: an empirically backed research agenda for a nascent field, Review of Managerial Science 12: 803-848. doi: https://doi. org/10.1007/s11846-018-0283-2. 
Schwab, K. (2016). The Fourth Industrial Revolution, New York: Penguin Random House.

Sommer, L. (2015). Industrial revolution - Industry 4.0: are German manufacturing SMEs the first victims of this revolution? Journal of Industrial Engineering and Management 8(5): 1512-1532. doi: http://dx.doi.org/10.3926/jiem.1470.

Sørensen, O. H., Hasle. P., Hesselholt, R. R. \& Herbøl, K. (2012). Nordisk forskningsperspektiver på arbeidsmiljø. [Nordic Research work environment perspectives] TemaNord: 525, 1-110. ISBN 978-92-893-2353-6.

Stock, T. \& Seliger, G. (2016). Opportunities of sustainable manufacturing in Industry 4.0, Procedia CIRP 40: 536-541. doi: https://doi.org/10.1016/j.procir.2016.01.129.

Tarafdar, M., Tu, Q., Ragu-Nathan, T. S. \& Ragu-Nathan, B. S. (2011). Crossing to the dark side: examining creators, outcomes, and inhibitors of technostress, Communications of the ACM 54(9): 113-120. doi: https://doi.org/10.1145/1995376.1995403.

Thoben, K. D., Wiesner, S. \& Wuest, T. (2017). 'Industrie 4.0' and smart manufacturing - a review of research issues and application examples, International Journal of Automation Technology 11(1): 4-19. doi: https://doi.org/10.20965/ijat.2017.p0004.

Tortorella, G., Miorando, R., Caiado, R., Nascimento, D. \& Staudacher, A., P. (2018). The mediating effect of employee's involvement on the relationship between Industry 4.0 and operational performance, Total Quality Management and Business Excellence [Online version]. doi: https://doi.org/10.1080/14783363.2018.1532789.

Torvatn, H., Kløve, B., \& Landmark, A. (2017). Ansattes syn på digitalisering [Employees vision about digitalization], Trondheim: SINTEF Report 2017:00681. ISBN: 978-821406679-1.

Wang, L., Törngren, M. \& Onori, M. (2015). Current status and advancement of cyber-physical systems in manufacturing systems, Journal of Manufacturing Systems 37: 517-527. doi: https://doi.org/10.1016/j.jmsy.2015.04.008 